\title{
Cristo si è fermato a Eboli, de Carlo Levi (1945) \\ e Francesco Rosi (1979): memórias da cor de olhos tristes
}

\author{
Cristo si è fermato a Eboli, by Carlo Levi (1945) \\ and Francesco Rosi (1979): memoirs of sad eyes' colours
}

\section{RESUMO}

Gabriela Kvacek Betella ${ }^{1}$

Como gênero híbrido a narrativa de Carlo Levi é relato objetivo e elaboração subjetiva equalizados numa forma literária. Escrito entre 1943 e 1944, o livro evoca com ares de memória o período de 1935 e 1936, o exílio do escritor. O filme baseado no relato fragmenta o cotidiano da região problemática e faz sobressair a verdade almejada pelos discursos compostos em tempos de crise, reforçada pela ação e expressão sem provincianismo e sem aristocratismo compensatório. É possível ver uma incapacidade até certo ponto natural do filme de Rosi ao traduzir a síntese de tratamento literário e reflexão histórico-social. Por isso é necessário ler a adaptação como atitude sobre a matéria literária e resultado da experiência histórica. O caráter memorialístico se firma no artifício que aproveita a abertura do livro, o curto monólogo do autor, moldura da narrativa. A presença da pintura materializa as questões sobre o absurdo contido nas telas.

Palavras-chave: Gêneros híbridos. Literatura e cinema. Carlo Levi. Francesco Rosi

\section{ABSTRACT}

As a hybrid genre, the narrative of Carlo Levi is an objective account and subjective elaboration that are equalized in a literary form. Written between 1943 and 1944, the book evokes with an atmosphere of memoir the period of 1935 and 1936, the writer's exile. The film based on the narration fragmentizes the daily life of the problematic region and highlights the truth aimed by the discourses composed in times of crises, reinforced by action and expression without provincialism and also without a compensating aristocratic pose. It is possible to see some incapacity of the film by Rosi, natural to a certain degree, to translate the synthesis of literary treatment and socio-historical reflection. For this reason it is necessary to read the adaptation as an attitude about the literary matter and the result of historical experience. The memoir character relies on the artifice that makes good use of the book's opening, the author's short monologue, its narrative frame. The presence of paintings materializes the questions about the absurd contained in them.

Key words: Hybrid genres. Literature and Cinema. Carlo Levi. Francesco Rosi

\footnotetext{
${ }^{1}$ Bacharel em Letras (italiano) pela FFLCH-USP, com mestrado e doutorado pela mesma instituição, ambos em Teoria Literária e Literatura Comparada. Especialista em gêneros literários híbridos. Atualmente na área de Literatura e Cinema, além de professora no ensino superior. abrielakvacek@uol.com.br
}

Cad. de Pesq. Interdisc. em Ci-s. Hum-s., Florianópolis, v.11, n.98, p. 50-64, jan/jun. 2010 
"Toda história é remorso" Carlos Drummond de Andrade

O livro mais conhecido do escritor, pintor e político Carlo Levi (1902-1975) é o resultado de uma experiência de prisão política, de exílio em seu próprio país. Durante o transcorrer da guerra da Abissínia, Levi é obrigado a viver numa região do sul da Itália, nas aldeias de Grassano e Aliano - esta última assume na narrativa o nome de Gagliano. O filme de Francesco Rosi se baseia no relato com bastante fidelidade, mantendo as impressões do exilado através das diversas histórias de habitantes locais que compõem a obra, desenhando um painel de homens e mulheres a mostrar, por exemplo, as razões da emigração, a exclusão dessa população pelo Estado, o misticismo religioso, as tristes condições de saúde. À medida que o protagonista se envolve com as pessoas - inclusive por causa de sua formação em medicina - sua resposta humanitária também aparece na pintura. Várias passagens do texto relembram o contato e a curiosidade dos moradores da região com os hábitos do pintor, que pacientemente acolhe ajudantes e modelos, especialmente crianças.

Levi é liberado do confino (confinamento) ${ }^{2}$ assim que o conflito na Abissínia chega ao fim, para triunfo da instância fascista da aldeia, que censurava as cartas do confinado e Ihe impedia o exercício da medicina, com toda burocracia própria do autoritarismo e da vigilância, relativizados no livro e reforçados no filme.

\section{LA COMPRESENZA DEI TEMPI}

Cristo si è fermato a Eboli (Cristo parou em Eboli) é produzido num tempo em que se fazia necessário sobretudo narrar, melhor dizendo, no tempo em que os registros do que dizia respeito à destruição material e humana de uma guerra eram legitimados por um veículo artístico. Carlo Levi escreveu o livro em Florença, entre

\footnotetext{
${ }^{2}$ Confino era o nome de uma medida policial adotada nos anos de 1930 para substituir a prisão domiciliar. Consistia em impor ao condenado a transferência por um determinado tempo para uma região distante da de sua residência ou de seu delito.

Cad. de Pesq. Interdisc. em Ci-s. Hum-s., Florianópolis, v.11, n.98, p. 50-64, jan/jun. 2010
} 
dezembro de 1943 e julho de $1944^{3}$, período decisivo do conflito e - particularmente na Itália - de intensas reviravoltas e grande tensão, devido à divisão de forças no país e à violência instaurada.

Vale lembrar que em 25 de julho de 1943, o rei Vittorio Emanuele III assumira o comando das forças armadas e destituíra Benito Mussolini, que então é preso e substituído pelo marechal Badoglio, que forma o novo governo. Como o país se pronunciava contrário ao fascismo (nessa altura, dito nazifascismo), o partido fascista é dissolvido, mas a continuação da guerra é proclamada, com o país ainda aliado à Alemanha. São estabelecidos acordos secretos com os Aliados (que intensificavam os bombardeamentos contra a Itália) e em 3 de setembro o general Castellano assina a capitulação das forças italianas (o "armistício curto"), anunciada somente no dia 8. Badoglio ordena a cessação das hostilidades contra as tropas americanas e declara guerra à Alemanha, cujas divisões numerosas haviam se tornado exército de ocupação, enquanto o rei, a corte e os membros militares de seu governo abandonam Roma e se refugiam no sul, em Bríndisi, já nas mãos dos Aliados. Em meio à total falta de direção no comando, o exército italiano se dispersa: parte volta para casa, outros entram na guerrilha contra os alemães. Civis e militares são presos e deportados para campos de concentração ou para fábricas de material bélico na Alemanha. O país está dividido. No Sul libertado pelos Aliados, Badoglio governa em nome da Monarquia. O Centro e o Norte estão ocupados pelas tropas nazistas. Em 12 de setembro de 1943, Mussolini é libertado da prisão pelos alemães e proclama, no dia 23, a República Social Italiana (RSI), que vigora até 25 de abril de 1945. A sede desse governo se estabelece no norte do país, em Salò (na região de Brescia, às margens do Garda). Durante essa chamada República de Saló o fascismo, em seus estertores, se torna ainda mais brutal e sanguinário. Em Roma, o Comitato di Liberazione Nazionale (CLN), que une os partidos antifascistas, não é reconhecido pelos anglo-americanos como governo legítimo, estatuto concedido apenas ao rei e ao marechal Badoglio. Em 26 de setembro Badoglio assina o "armistício longo", traduzindo a "rendição incondicional" que o 3 de setembro tentara

\footnotetext{
${ }^{3}$ O livro aparece primeiro aos capítulos na revista I/ Ponte, fundada em janeiro de 1945 e dirigida por Piero Calamandrei. Menos famosa que II Politecnico, a revista privilegia assuntos políticos, econômicos e sociais. Inspirada nos ideais da Resistência, II Ponte procurava não mitificar aqueles tempos dramáticos, mas manter os ideais humanistas, a dignidade coletiva após a ruína deixada pela guerra e pelo fascismo.
}

Cad. de Pesq. Interdisc. em Ci-s. Hum-s., Florianópolis, v.11, n.98, p. 50-64, jan/jun. 2010 
evitar. Noutro documento, os Aliados reconhecem a aliança com a Itália, desde que esta declare guerra à Alemanha, o que acontece em 13 de outubro. Depois disso, Vittorio Emanuele renuncia em favor do filho e Roma é libertada em 4 de junho de 1944, com o avanço dos Aliados ${ }^{4}$.

Levi não trata desse presente, mas da experiência evocada do período de 1935 e 1936, quando é levado como confinato à Lucania ${ }^{5}$ (Basilicata) por causa das atividades políticas antifascistas. A frase que abre o livro, "Passaram-se muitos anos, cheios de guerra e do que se costuma chamar de História" (LEVI, 1986, p. 11) destaca o tempo que separa o presente da composição do passado dos fatos narrados. $\mathrm{O}$ autor define logo nas primeiras linhas o seu processo e as condições sob as quais põe em prática a empreitada da memória:

(...) fechado numa sala, um mundo fechado, é agradável retornar, através das lembranças, àquele outro mundo, encerrado no sofrimento e nos costumes, este mundo à margem da História e do Estado, eternamente paciente, onde o camponês vive, na miséria e no afastamento, a sua vida imóvel numa terra árida, diante da morte. (LEVI, 1986, p. 11)

Ao longo da narrativa, no exercício de retrocesso no tempo, esse narrador prova novamente o gosto da acolhida durante a qual os conceitos do homem do norte não valem muito no mundo que concentra uma força histórica tremenda, capaz de provocar a reflexão sobre outras realidades e, certamente, de potencializar os problemas do presente. Isso acontece quando o narrador parece emitir um juízo que, embora se refira aos efeitos da Primeira Guerra Mundial, avalia o estado perene de sofrimento, isolamento e estranheza da região:

Nem mesmo a grande guerra, tão violenta e ainda tão próxima, interessava aos camponeses. Tinham-na suportado e agora era como se a tivessem

\footnotetext{
${ }^{4}$ Durante o inverno de 1944-1945 o avanço dos Aliados no centro da península decresce, mas a Resistência não irá recuar até abril de 1945, quando a "linha gótica" é vencida. No dia 28 de abril Mussolini é executado após tentar a fuga para a Suíça e, no dia 29, as tropas alemãs na Itália assinam sua rendição. Terminava a luta pela libertação e, embora em ruínas, a Itália saía moralmente renovada dos fatos trágicos do período 1943-1945. Toda esta síntese histórica se baseia no aparato de FABRIS, 1996, p. 34-7.

${ }^{5}$ Para estrangeiros, normalmente o nome Lucania também designa a região da Basilicata, situada entre a Calábria, Campania e Puglia. No entanto, a primeira denominação remonta a um período anterior à conquista pelos romanos, quando se referia a um território mais amplo, incluindo partes da Calábria e da Campania. A região passou a se chamar Basilicata a partir do século XIII e oficialmente mantém este nome até hoje, à exceção do período entre 1932 e 1947, quando voltou a se chamar Lucania, nome que os habitantes da região preferem, por razões ligadas às suas origens e à própria história.
}

Cad. de Pesq. Interdisc. em Ci-s. Hum-s., Florianópolis, v.11, n.98, p. 50-64, jan/jun. 2010 
esquecido. Ninguém costumava se vangloriar de seus feitos, nem contar aos próprios filhos em quais batalhas combatera, nem mostrar os ferimentos ou lamentar-se dos sofrimentos. Se eu lhes perguntava alguma coisa, respondiam com brevidade e indiferença. Tinha sido uma grande desgraça, suportada como todas as outras. Aquela também tinha sido uma guerra de Roma. Igualmente naquela época, haviam seguido as três cores que aqui parecem estranhas, as cores heráldicas de uma outra Itália, incompreensível, voluntária e violenta. Esse vermelho, insolente e alegre, e esse verde, absurdo por aqui, onde mesmo as árvores são cinzentas, onde a relva não brota da argila. Essas cores e todas as outras são para os nobres. Estão bem nos escudos dos senhores ou sobre os pavilhões das cidades. Que possuem em comum com as cores dos camponeses? Sua cor é apenas uma, aquela mesma de seus olhos tristes e de suas roupas, que não é uma cor mas sim a escuridão da terra e da morte. (LEVI, 1986, p. 161)

É justo deduzir que o momento de narrar pedia uma atitude que aliasse o ponto de vista aos acontecimentos imediatos, mas também pode ser legítimo reconhecer a capacidade do discurso memorialístico de ampliar o espectro das reflexões. Ao localizar os tempos da escrita e dos fatos, o texto passa a funcionar inevitavelmente nas duas direções, mesmo com a situação de "exílio voluntário" do espírito no passado. Não é demais ressaltar que a experiência particular se imbui de universalidade ao oferecer contribuição ao debate de temas como a "questão meridional" italiana e o subdesenvolvimento de outras partes do mundo, graças à consciência da realidade trágica incorporada pela forma literária (CANDIDO, 1989) e, no caso do fragmento acima, redirecionada pelo escritor que evoca a memória com ajuda do olhar do pintor.

Em 1963, Carlo Levi escrevia ao editor Giulio Einaudi para comentar a nova edição do livro escrito vinte anos antes. Declarava sua consciência da reelaboração dos fatos descritos, pois desenvolvera "com o auxílio da memória, não apenas os acontecimentos do passado, mas também a contemporaneidade infinita e poética dos tempos e dos destinos" (LEVI, 1986, p. 5). Em seu "refúgio contra a morte feroz" em 1943-1944 a memória dos anos de 1935-1936 se tornava uma forma de enfrentamento da matéria trágica, caótica e catastrófica que se punha diante dele. $\mathrm{O}$ livro era uma defesa confessa, mas cerca de trinta anos depois do vivido o autor ainda pode concluir que o momento da escrita também havia sido uma forma de reviver o outro "eu", aquele que descobrira "a história além da história, o tempo fora do tempo, a dor antes de nada mais, e a si mesmo" (LEVI, 1986, p. 7) através da 
reformulação da experiência que o levou à região então praticamente desconhecida do sul da Itália.

Trabalhando com a matéria da experiência o autor preserva sua reflexão, num certo sentido, dos horrores da guerra presente, porque essa memória forma seu acervo de pesquisa, que não pode ser retirado por imposição, não é saqueado, nem retido, nem confiscado. $O$ estilo de narrar transcende o mero relato passivo de lembranças e é atrativo, pois reelabora as imagens da memória durante o próprio ato da narração, daí a vivacidade impressionante. A dramaticidade do discurso de Carlo Levi é sutil, mascarada pelo caráter ensaístico que parece se colocar no tom certo. Não há marcas de romanesco e, contudo, existe o poder de sedução de um romance. Boa parte dessa atração está associada à microhistória traçada pelo cotidiano da Lucania:

Uma noite, ao escurecer, mais ou menos no final de outubro, chegou a minha casa um camponês para renovar o curativo de um abscesso. Atirei ao chão da sala as gazes e algodões sujos e chamei Giulia para que os varresse. Esta observava nessa casa o costume de Gagliano de atirar o lixo para o meio da rua através da porta. Todos agem assim e os porcos, depois, tratam de fazer a limpeza. Entretanto, naquela noite, notei que a mulher juntava tudo e deixava em casa, perto da soleira da porta. Perguntei por que fazia aquilo.

- A noite já caiu - respondeu-me ela -, não posso varrer nada para o meio da rua. o anjo, não se sabe, poderia ficar zangado. - E continuou sua explicação, espantada por eu ignorá-la. - Em toda casa, ao crepúsculo, descem três anjinhos. Um fica junto à porta, outro fica à mesa e o terceiro na cabeceira da cama. Protegem a casa e a defendem. Nem os lobos nem os espíritos maus podem entrar durante toda a noite. Se eu atirasse o lixo através da porta, poderia jogá-lo no rosto do anjo que não se vê. Ele se sentiria ofendido e nunca mais voltaria. Amanhã de manhã, ao nascer do sol, jogarei fora o lixo depois que o anjo tiver partido. (LEVI, 1986, p. 179180)

A perspectiva da descoberta não esmorece com os verbos no passado - e assim como o narrador permanece surpreso, por vezes assustado, o leitor também estranha aquele território tão longe do progresso civil, tão destacado e tão encravado no país que traça a sua História e sua glória com as guerras, mantendo incoerências. Tal perspectiva é sabiamente utilizada, uma vez que o leitor se aproxima dos fatos sem deixar de estar consciente da mediação, como acontece durante o relato do encontro entre o narrador e o coveiro de Gagliano, cheio de simbologias e carregado de força metafórica: 
O terreno estava cheio de ossos que afloravam de velhas sepulturas, corroídos pelas águas e pelo sol; velhos ossos brancos e calcinados. Para o velho os ossos, os mortos, os animais e os demônios eram coisas familiares, ligadas, como o são aliás aqui para todos, a vida simples de cada dia.

- A aldeia é feita de ossos dos mortos - dizia-me ele no seu jargão obscuro, gorgolejante, como uma corrente subterrânea que irrompe, inesperadamente, por entre as pedras; e fazia, com aquele buraco desdentado que lhe servia de boca, uma careta que talvez fosse um sorriso. Se eu tentava fazê-lo explicar o que pretendera dizer, não me dava ouvidos, mas gargalhava e repetia, sem mudá-la, a mesma frase, recusando-se a acrescentar fosse lá o que fosse. - É isso mesmo, a aldeia é feita com os ossos dos mortos.

De qualquer forma, o velho tinha razão, não importa se o devêssemos entender de um modo figurado e simbólico, ou se aceitássemos a coisa ao pé da letra. Quando, algum tempo mais tarde, o podestade mandou abrir um buraco, não muito longe da casa da viúva, para colocar os alicerces de uma casinha, obra do regime, para servir de sede dos balilla, em vez de se encontrar terra a dois palmos de profundidade, foram achados milhares de ossos humanos. Durante vários dias a aldeia foi atravessada por carrinhos cheios dos restos mortais de nossos antigos parentes para serem atirados, lá embaixo, no fundo da Fossa del Bersagliere.

Mais recentes, e ainda não tão calcinados como os do cemitério, eram os ossos dos túmulos situados sob o chão da igreja da Madonna degli Angeli, a igreja desmoronada. De alguns deles ainda pendiam tiras ressecadas de carne ou de pele seca. Os cachorros desenterravam-nos, disputavam entre si a sua posse, correndo com uma tíbia na boca e latindo, furiosos, subiam as ladeiras da aldeia. Aqui, onde o tempo não passa, é perfeitamente normal que os ossos recentes, menos recentes, ou muito antigos aflorem indistintamente sob os pés dos transeuntes. (LEVI, 1986, p. 84-86)

Talvez não seja leviano enxergar nessas imagens o terror da morte materializada nos restos humanos à tona, suspensos no tempo, como a acumular a morte de todos os tempos. Revelada aos olhos do estranho, causa tanta perplexidade que, ao recompor as imagens no livro, o escritor utiliza o indireto livre para de algum modo se apossar um pouco da história e reviver o efeito. Infelizmente, a cena não é bem aproveitada no filme, ao atingir um tom próximo ao cômico, provavelmente estimulado pela descrição do velho coveiro que gargalhava. Propositadamente ou não as imagens estabelecem forte ligação com o momento presente da escrita, ainda que não levemos em conta as descrições dos massacres em campos de concentração nazistas e pensemos apenas na morte nos campos de batalha e em meio às cidades.

É possível que Levi estivesse cristalizando as imagens que lhe chegavam do trágico conflito presente em 1944 na cena no cemitério, presenciada na década anterior. Com isso, sua narrativa adquire uma espécie de valor profético, um sentido 
a posteriori. De qualquer forma, vale dizer que a situação de abandono dos mortos intensifica a morte que de fato esteve exposta tanto num tempo quanto no outro, e aqui adquire a força da imagem literária.

\section{ASPIRAÇÃO REVOLUCIONÁRIA}

Francesco Rosi começou na carreira como assistente de direção de Luchino Visconti em La terra trema, de 1948. Dirige desde 1958, com algumas investidas como roteirista. Filma Cristo si è fermato a Eboli em 1978, sob condições ideológicas favoráveis para revisitar a "questão meridional" ou, pelo menos, para revisar o significado dela para o período retratado (1935-1936), para o pós-guerra (época da publicação do livro) e para o seu presente, tarefa complexa devido às camadas sucessivas de teorias até então acumuladas sobre as formas adequadas de representação histórica. $\mathrm{O}$ diretor declarou que fizera um filme sobre os problemas da Lucania dos anos de 1930 ao invés de retratar o presente porque os problemas são, em linhas gerais, os mesmos. Acresce-se o fato de que era possível encontrar no Sul alguns problemas idênticos aos do Norte, como no que diz respeito aos jovens e seu futuro. Sendo na maioria filhos de camponeses, os jovens do Sul à década de 1970 estudaram e se formaram em direito, engenharia, etc. Porém vivem o dilema de recusar a herança camponesa e seus modos de vida e de trabalho, enquanto o diploma não serve para muita coisa ${ }^{6}$.

Há no filme de Rosi intenções de atualização dos propósitos do livro, na retomada de situações como as histórias do brigantaggio ${ }^{7}$ e a guerra da Abissínia, episódios que afetaram profundamente a vida do sul da Itália e que, retomados pelo

\footnotetext{
${ }^{6}$ A entrevista com Francesco Rosi é parte do Documentario dell'archivio RAl $A$ sud di Eboli: viaggio nel cinema di Francesco Rosi (1979), a cura di Tullio Kezich, incluído nos extras do DVD Cristo si è fermato a Eboli.

${ }^{7}$ Brigantaggio é um termo que originariamente se refere a fenômenos de banditismo, porém costuma definir uma forma de insurreição política e social despertada sobretudo na Basilicata, na Campania e em Abruzzo durante o processo de unificação da Itália e na primeira década da monarquia. $O$ brigantaggio ou guerra dos briganti se desenvolve depois da proclamação da unidade italiana e foi ao mesmo tempo guerrilha de grupos fiéis aos Bourbons contra a unificação e fenômeno social de revolta contra abusos, quase símbolo de justiça popular. Os participantes da resistência foram chamados de briganti pelos militantes da unificação, com um sentido bastante depreciativo. Brigante é um termo genericamente empregado no sentido de fora da lei e frequentemente é utilizado, carregado do sentido depreciativo, para definir combatentes e revoltosos em determinadas situações sociais e políticas.
}

Cad. de Pesq. Interdisc. em Ci-s. Hum-s., Florianópolis, v.11, n.98, p. 50-64, jan/jun. 2010 
escritor e pelo cineasta, não somente relativizam o presente de cada um, ajustando o instrumental crítico, mas atuam como apropriação do passado de um povo, de uma nação, solidarizando-se com as regiões menos privilegiadas, dando-lhes voz. Nessa altura, pode-se estabelecer um paralelo com as palavras de Walter Benjamin quando este afirma nas tão citadas teses sobre a história: "nada do que um dia aconteceu pode ser considerado perdido para a história" e "somente a humanidade redimida poderá apropriar-se totalmente do seu passado", ou seja, "somente para a humanidade redimida o passado é citável, em cada um de seus momentos. Cada momento vivido transforma-se numa citation à l'ordre du jour - e esse dia é justamente o do juízo final." (BENJAMIN, 1993, p. 223). Conforme se observa, livro e filme cumprem a expiação da "viagem na terra do remorso", conforme definiu o próprio diretor em $2002^{8}$.

Do ponto de vista da realização do filme, uma aposta ousada na indicação temporal acontece logo na abertura, antes dos créditos iniciais, quando nos é mostrado um protagonista envelhecido, com características físicas de Carlo Levi nos últimos anos de sua vida, a refletir sobre os anos que passaram ("Sono passati molti anni, pieni di guerra..."). A cena é tocante, pois evoca a última imagem do artista e do homem público recluso e abatido. A caracterização deixa dúvidas, no entanto, sobre a localização dessa cena no tempo, sendo possível aceitar que esse momento da narrativa (a composição das memórias da Lucania e uma espécie de prólogo que as introduz no livro) é transferido dos anos de 1940 para os anos de 1970. Rosi altera o tempo da recordação criando uma espécie de "pluridimensionalidade" do tempo.

Especialmente, a cena de abertura do filme modifica a expressão do discurso da memória, pois o protagonista não escreve. Visivelmente emocionado, ele recorda os seus camponeses através dos retratos que fizera de vários deles, quadros que aparecem um a um enquanto sua voz declama em off o primeiro parágrafo do livro. Os retratos antecipam as histórias que serão apresentadas e, terminado o filme, permanecem como registros das mesmas, conforme se percebe na última imagem (que acolhe os créditos finais), correspondente ao primeiro retrato na cena de

\footnotetext{
${ }^{8}$ Francesco Rosi, durante o Festival de Cinema di Torino, para a apresentação de Cristo si è fermato a Eboli, em 29 de outubro de 2002, Museo del Cinema, Torino. A fala constitui um pequeno recorte no "Speciale Francesco Rosi", presente nos extras do DVD Cristo si è fermato a Eboli.

Cad. de Pesq. Interdisc. em Ci-s. Hum-s., Florianópolis, v.11, n.98, p. 50-64, jan/jun. 2010
} 
abertura, no qual uma criança sentada olha para trás com uma expressão forte e desafiadora, a despeito dos olhos negros e tristes, para os quais a câmera se direciona no lento close-up, devolvido ao protagonista que é focalizado do mesmo modo, com seu olhar identificado com o olhar da criança.

Esse movimento, repetido a cada retrato na cena de abertura, reflete 0 movimento de memória que o personagem encena, sobrepondo o discurso sobre o prazer de retornar ao mundo camponês à humanidade dos fatos, materializada na pintura, assim como também expressa a frustração. O filme reconstrói para o espectador a noção de pintura de Carlo Levi: além de promover um processo epistemológico, ela pode fazer dessa noção uma metáfora para o modo de narrar e de filmar. Quando o filme avança, vale lembrar que o primeiro plano se torna mais raro, como se passasse a evitar o ponto de vista interior. Nesse sentido, o filme acompanha a perspectiva inovadora da memória de exílio utilizada por Levi.

Podemos situar Cristo si è fermato a Eboli como resultado da experiência do sujeito visto por si mesmo e pelos outros como um estranho naquele meio, como alienado de suas condições. A reação possível contra essa suspensão passa, no caso de Carlo Levi, pela instância intelectual, cujo produto é a escrita, um meiotermo entre narrativa e ensaio. Em meio à produção literária neorealista, o livro mais conhecido desse escritor não se enquadraria nos gêneros literários tradicionais por ser um pouco diário, ensaio histórico e sociológico, testemunho, reflexão e descrição de cenas de vida camponesa - hoje em dia, pode figurar entre os gêneros híbridos. O que mais importa ressaltar é a aliança entre descrições fartas em plasticidade e expressão de pensamento crítico. Se levamos em conta que o elo se forma sob uma narrativa de memória com vigor quase de uma crônica de viagem, temos uma literatura empenhada e munida de recursos dispostos a representar os problemas sociais e o "voo das preocupações" existenciais. Para isso, a narrativa se despe da reflexão psicológica e da posição tradicional do "eu" como centro e assume o estatuto de memória coral. Valoriza a terra e suas particularidades, numa espécie de proposta "regionalista" que estimula a reação, presente no final do livro em forma de desabafo ideológico atualizado para os anos de guerra e de fascismo. De certo modo, o conteúdo profético desmistifica as relações debatidas pela esquerda tradicional e demonstra, no mínimo, frieza analítica em tempos de sangue quente: 
Costuma-se dizer que o grande inimigo é o latifúndio, o grande proprietário e, evidentemente, lá onde o latifúndio existe, ele está longe de ser uma instituição benéfica. Entretanto, se o grande proprietário que reside em Nápoles, Roma ou Palermo, é um inimigo dos camponeses, não é, todavia, o maior nem o mais intolerável. Pelo menos ele está longe e não pesa diariamente sobre a vida de todos. O verdadeiro inimigo, aquele que impede toda a liberdade e toda a possibilidade de existência civil aos camponeses, é a pequena burguesia das aldeias. É uma classe degenerada, física e moralmente, incapaz de cumprir sua função e que só vive de pequenas rapinas e da tradição degenerada de um direito feudal. Até esta classe ser suprimida e substituída, não se poderá pensar em resolver o problema meridional.

Este problema, no seu tríplice aspecto, já existia anteriormente ao fascismo; mas o fascismo, silenciando a seu respeito e negando-o, levou-o ao seu ponto máximo, porque com ele o estatismo pequeno-burguês chegou à mais completa afirmação, ao seu apogeu. Não podemos, hoje, prever quais as formas políticas que se preparam para o futuro; contudo, num país de pequena burguesia como o é a Itália, onde as ideologias do pequeno-burguês conseguiram contaminar até mesmo as classes populares citadinas, é, infelizmente, provável que as novas instituições que se seguirão ao fascismo, através de uma evolução lenta ou por obra da violência, e mesmo que surjam $d$ um movimento extremista e aparentemente revolucionário, serão levadas a revalorizar, sob uma outra forma, as antigas ideologias; recriarão um Estado tão distante da vida, tão sacrossanto e abstrato quanto o outro. Sob novos nomes e bandeiras, perpetuaremos, mais agravado ainda, o eterno fascismo italiano. Sem uma revolução campestre, jamais teremos uma verdadeira revolução italiana e vice-versa. As duas coisas se identificam. $O$ problema meridional não se resolve dentro do Estado atual, nem dentro daqueles que, sem o contradizerem radicalmente, o seguirão. (LEVI, 1989, p. 294-295)

Nesta passagem, um dos poucos momentos no livro em que o intelectual político vem à tona na narrativa, o memorialista reflete e dá um parecer sobre as lembranças que até então vinha recompondo. Se por um lado o narrador profetiza sobre os destinos das relações de classe e relativiza suas consequências no país, por outro ele não pode apresentar soluções além de pregar "um novo Estado, que não pode ser nem aquele fascista, nem liberal, nem comunista (...)" (LEVI, 1989, p. 296). Baseado na ideia de Estado e seus fundamentos, sustenta a autonomia do indivíduo formando um conjunto de autonomias infinitas, de todas as formas da vida social. O raciocínio é inserido na lembrança de um percurso entre Grassano e Gagliano, como se o pensamento tivesse sido elaborado pelo protagonista durante a viagem, o que sabemos ser um dos efeitos do enredamento da narrativa. Todavia, Levi só poderia pensar e escrever a passagem acima em 1944, com todas as limitações que o contexto imprimia. 
Cabe investigar, pelo menos para dar início a uma discussão que não se encerra aqui, até que ponto a representação do povo camponês, com toda tendência progressista que afiança, mantém características pequeno-burguesas, provincianas e politicamente moderadas, que denotam, na concepção de Asor Rosa (1965), uma posição populista, medida que o crítico adota para Levi e outros autores neorealistas como Vasco Pratolini e Elio Vittorini ao delinear o comportamento redentor assumido pelas gerações de intelectuais italianos enquanto outras literaturas européias negavam-se a desempenhar esse papel. A argumentação pode ser longa, pois tende a envolver outras questões sobre o desempenho dos intelectuais e escritores numa cultura durante um período crítico como o pós-guerra, assim como inclui os efeitos de padrões sociais burgueses mais ou menos avançados sobre a produção literária. Se a representação implicava falta de modernização e de iniciativa estética capaz de romper com os ideais de função socialmente regeneradora da arte, um dos interesses no momento de 1944-1945 era, pelo menos no tocante a Cristo si è fermato a Eboli, expressar a impotência do intelectual e o valor da experiência do contato direto com efeitos inesperados e fidedignos das ideologias.

É possível dizer que a transposição do livro para o cinema aproveita o registro da vida camponesa ligada ao ritmo da natureza, às superstições, à magia elevada ao posto de ciência. Ao lado disso, se serve das cenas em que aparecem as necessidades reais cuja soma é a marginalização das aldeias em relação ao restante do país e também da discrepância interna, quando mapeia a contradição entre os galantuomini (homens de bem) a saborear biscoitos e os camponeses padecendo com a malária.

O filme continua a rejeitar a imposição política e econômica pensada por Levi, mas amplia o espectro de relativização, a começar pela utilização da trilha sonora que vai das canções fascistas a canções napolitanas, cujo efeito sobre o espectador inclui a passagem do tempo e as consequências de outras catástrofes. Sobressai uma consciência extremada através da verdade almejada pelos discursos compostos em tempos de crise, reforçada pela ação e expressão sem provincianismo e sem aristocratismo compensatório, para aproveitar a expressão de Antonio Candido (1989). Nesse sentido, podemos dizer que o filme, realizado após 
as discussões sobre o caráter populista da literatura neorealista, tenta enfocar e ampliar a consciência que transborda do livro.

Segundo Lino Micciché (1979), o conteúdo do filme traz à tona um mundo que aparentemente interrompe uma sucessão de radiografias do poder na insigne filmografia de Rosi ${ }^{9}$. No entanto, o diretor que concebeu seus filmes como instrumentos de investigação e denúncia nos apresenta as nuances funestas e degradadas do poder em Cristo si è fermato a Eboli através do podestà ${ }^{10}$, do cobrador de impostos, da atitude do governo ao libertar o confinato "liberal" de Turim em 1936 e manter os confinados comunistas de Ancona e de Pisa. Mas o que fica latente é a incapacidade de ação do protagonista em várias cenas, coisa que chega a se confundir com a frustração que permanece no semblante cansado de um Carlo Levi que não encarna o mito redentor. Assim como no livro, as histórias não se resolvem, deixando várias interrogações e quase óbvias respostas a cargo do espectador, pois o protagonista não consegue dar solução para o desastre social.

Um dos episódios que encerram o filme refaz justamente a burocracia à qual o médico Levi se sujeita para ver um doente que sucumbe à morte na aldeia vizinha. Portanto, assim como é capaz de mostrar a torpeza, a manipulação, a corrupção pelos poderes, as memórias de Levi ainda atestam no final dos anos de 1970 a derrocada da utopia burguesa (segundo a qual a inserção na História seria suficiente para derrubar vícios primitivos). Nas palavras de Micciché (1979), Rosi quer dizer que não basta mudar o poder, é preciso mudar a qualidade de sua lógica. Visto por outro ângulo, o diagnóstico também pode se tornar um convite à reação diferente dos temores e nostalgias a relacionar o presente ao passado de opressão e repressão.

O filme de Rosi já contava com a assimilação das ciências humanas e da psicanálise, fenômenos muito comuns após os anos de 1960, quando o cinema atinge um grau de sofisticação, especialmente ao privilegiar a metáfora. Vale ressaltar que as discussões sobre o caráter populista da literatura de autores neorealistas também já estavam em pauta. Ainda assim, Rosi investiga o presente

\footnotetext{
${ }^{9}$ Destacamos sobretudo Le mani sulla città (1963), no qual denunciava a escandalosa atividade ilegal de várias sociedades imobiliárias em Nápoles e Uomini contro (1970), uma denúncia contra o mal absoluto através da procura das raízes da guerra descrevendo o conflito de 1914-1918 e sua loucura nacionalista (BRUNETTA, 2007; PRUDENZI e RESEGOTTI, 2006).

${ }^{10}$ Chefe da administração municipal (equivalente a prefeito) durante o regime fascista.
}

Cad. de Pesq. Interdisc. em Ci-s. Hum-s., Florianópolis, v.11, n.98, p. 50-64, jan/jun. 2010 
solidarizando-se corajosamente com as imagens de Carlo Levi, recompondo-as de modo a validar sua finalidade e o sentido mais amplo daquele exílio. A leitura da obra literária determinou, sem dúvida, as escolhas do cineasta, porém alguns princípios da adaptação evidenciam recursos equivalentes, isto é, revelam procedimentos dispostos a formalizar em imagem visual a especificidade da forma literária, que inclui o revisionismo livre de receio de lutar contra obstáculos reais - e, portanto, mais sereno e ciente da falácia dos obstáculos fictícios. 


\section{REFERÊNCIAS}

ASOR ROSA, A. Scrittori e popolo: il populismo nella letteratura italiana contemporanea. Torino: Einaudi, 1988.

BENJAMIN, W. Sobre o conceito de história. In: Magia e técnica, arte e política: Ensaios sobre literatura e história da cultura. Obras escolhidas. Tradução Sergio Paulo Rouanet. 5. ed. São Paulo: Brasiliense, 1993, p. 222-232.

BRUNETTA, G. P. Il cinema italiano contemporaneo: da La dolce vita a Centochiodi. Roma: Laterza, 2007.

CANDIDO, A. Literatura e subdesenvolvimento. In: e outros ensaios. 2. ed. São Paulo: Ática, 1989. p. $\overline{140-162 .}$

A Educação pela Noite

CRISTALDIFILM; ROSI, F. CRISTO si è fermato a Eboli. Produção de Cristaldifilm, direção de Francesco Rosi. Italia/França: Vides/RAI, 1978. 1 DVD (145 min.), son., color.

FABRIS, M. O neo-realismo cinematográfico italiano. São Paulo: Edusp, 1996.

LEVI, C. Cristo parou em Eboli. Tradução Wilma F. Ronald de Carvalho. Rio de Janeiro: Nova Fronteira, 1986.

LEVI, C. Cristo si è fermato a Eboli. 17. ed. Torino: Einaudi, 2003.

MICCICHÉ, L. Cristo si è fermato a Eboli. Cinemasessanta, gen./feb 1979. In: Cristo si è fermato a Eboli, DVD, 2003.

PRUDENZI, A. ; RESEGOTTI, E. Cinema político italiano: anos 60 e 70. São

Paulo: Cosac Naify, 2006.

Dossiê:

Recebido em: 05/04/2010

Aceito em: 21/04/2010 